\title{
A novel expression system for production of soluble prion proteins in E. coli
}

\author{
Romany NN Abskharon ${ }^{1,2}$, Stephanie Ramboarina ${ }^{1,2}$, Hassan El Hassan ${ }^{1,2}$, Wael Gad ${ }^{1,2,3}$, Marcin I Apostol ${ }^{8}$, \\ Gabriele Giachin ${ }^{5}$, Giuseppe Legname ${ }^{5,6,7}$, Jan Steyaert ${ }^{1,2}$, Joris Messens ${ }^{1,2,3}$, Sameh H Soror ${ }^{1,2,4^{*}}$ and \\ Alexandre Wohlkonig ${ }^{1,2^{*}}$
}

\begin{abstract}
Expression of eukaryotic proteins in Escherichia coli is challenging, especially when they contain disulfide bonds. Since the discovery of the prion protein (PrP) and its role in transmissible spongiform encephalopathies, the need to obtain large quantities of the recombinant protein for research purposes has been essential. Currently, production of recombinant PrP is achieved by refolding protocols. Here, we show that the co-expression of two different PrP with the human Quiescin Sulfhydryl OXidase (QSOX), a human chaperone with thiol/disulfide oxidase activity, in the cytoplasm of E. coli produces soluble recombinant PrP. The structural integrity of the soluble PrP has been confirmed by nuclear magnetic resonance spectroscopy, demonstrating that properly folded PrP can be easily expressed in bacteria. Furthermore, the soluble recombinant PrP produced with this method can be used for functional and structural studies.
\end{abstract}

\section{Introduction}

Prion diseases, also referred as transmissible spongiform encephalopathies (TSEs), are a family of rare progressive neurodegenerative disorders that affect both humans and animals [1]. TSEs include, for instance, bovine spongiform encephalopathy (BSE) in cattle, and Creutzfeldt-Jakob disease (CJD) in humans. These disorders are characterized by long incubation periods and characteristic spongiform changes in the brain associated with neuronal loss. The causative agent of TSEs is an infectious protein known as prion (also denoted as $\operatorname{PrP}^{\mathrm{Sc}}$ ) [2]. This pathogenic betasheet-rich conformer derives from the normal, mostly alpha-helical isoform, cellular prion protein $\left(\operatorname{PrP}\right.$ or $\left.\operatorname{PrP}^{\mathrm{C}}\right)$, through a conformational conversion event which leads to aggregates in the brains of affected individuals leading to neurodegeneration [3].

Since the identification of prions as the causing agent of TSEs, recombinant PrP has been instrumental to study the structural and biophysical aspects of prion amyloidosis [4].

Due to its easy handling, inexpensive medium and large-scale production, the enteric bacterium Escherichia coli $(E . c o l i)$ is the organism of choice for the production

\footnotetext{
* Correspondence: ssoror@vub.ac.be; awohlkon@vub.ac.be

${ }^{1} \mathrm{VIB}$, Department of Structural Biology, Brussels, Belgium

Full list of author information is available at the end of the article
}

of numerous recombinant proteins [5]. However, expression of mammalian proteins in $E$. coli remains difficult and often results in inactive aggregates because the recombinant proteins do not fold properly in this host [6]. For example, recombinant $\operatorname{PrP}$ is largely expressed as inclusion bodies [7]. Most refolding protocols require a large amount of reagents and are time consuming. Success is highly dependent on the experimenter's savoir-faire. Attempts to assist proper folding of the $\operatorname{PrP}$ in the cytoplasm of $E$. coli by co-expression with bacterial chaperones failed [8]. As the formation of a disulfide bond is essential for PrP proper folding, expression of full-length $\operatorname{PrP}$ in the periplasm of $E$. coli was also investigated, resulting in soluble PrP which is partially degraded at the unstructured $\mathrm{N}$-terminal end [9]. It has been observed that PrP can interact with several chaperones from the endoplasmic reticulum (ER) [10], including Pdia3 (also known as ERp57) and Grp58 (ERp60) [11], suggesting that in physiological condition, $\operatorname{PrP}$ requires assistance to fold into the correct conformation. In addition, $\operatorname{PrP}$ contains a disulfide bond which is crucial for the proper $\alpha$-helical fold [12]. Based on these observations, we investigated the use of QSOX as a folding catalyst for $\operatorname{PrP}$ in the cytoplasm of E. coli. QSOX is a human chaperone that introduces disulfide bonds in secreted
Ciomed Central

(c) 2012 Abskharon et al; licensee BioMed Central Ltd. This is an Open Access article distributed under the terms of the Creative Commons Attribution License (http://creativecommons.org/licenses/by/2.0), which permits unrestricted use, distribution, and reproduction in any medium, provided the original work is properly cited. 
proteins downstream of the ER [13], and has been shown to be enzymatically active in the bacterial cytoplasm [14].

In the present study, we describe for the first time the production of soluble PrP of both mouse (MoPrP) and human (HuPrP) using co-expression with QSOX in the E. coli cytoplasm.

\section{Materials and methods Plasmids Construction \\ Human PrP (HuPrP): full length (23-231) and truncated (90-231)}

Cloning of $\mathrm{HuPrP}(90-231)$ into pET-28a (Novagen) was performed as described previously [15]. HuPrP(23-231) was subcloned from the plasmid $\mathrm{HuPrP}(23-231) / \mathrm{pET}$ 11a [16] into pET-28a as BamHI-NdeI fragment using the standard molecular biology techniques.

Mouse PrP(MoPrP): full length (23-230) and

truncated (89-230)

Cloning of MoPrP(23-230) and $\operatorname{MoPrP}(89-230)$ as described previously [15].

\section{QSOX}

The human QSOX plasmid was a generous gift from Prof. Colin Thorpe [13].

\section{Protein expression}

\section{Small-scale expression trials}

Each PrP construct and the QSOX plasmid were co-transformed into E. coli Rossetta (DE3) pLysS and plated on LB-agar supplemented with $100 \mu \mathrm{g} / \mathrm{mL}$ ampicillin and $25 \mu \mathrm{g} / \mathrm{mL}$ kanamycin. A single colony was used to inoculate a $25 \mathrm{~mL}$ pre-culture (LB medium supplemented with $100 \mu \mathrm{g} / \mathrm{mL}$ ampicillin and $25 \mu \mathrm{g} / \mathrm{mL}$ kanamycin). The following day, a $25 \mathrm{~mL}$ culture was inoculated with $1 \mathrm{~mL}$ of the pre-culture. Cells were induced at $\mathrm{A}_{600}=0.7$ by adding $1 \mathrm{mM}$ isopropyl-b-D-thiogalactopyranoside (IPTG). After induction culture was incubated overnight $(16 \mathrm{~h})$ at $15^{\circ} \mathrm{C}$. Harvested cells were resuspended in lysis buffer: $0.1 \mathrm{~g}$ of cell paste/mL of $50 \mathrm{mM}$ potassium phosphate, $\mathrm{pH} 7.5$, $300 \mathrm{mM} \mathrm{NaCl}$ supplemented with $0.1 \mathrm{mg} / \mathrm{mL}$ lysozyme, $0.1 \mathrm{mg} / \mathrm{mL}$ ABESF and $1 \mu \mathrm{g} / \mathrm{mL}$ leupeptin. The lysate was sonicated 4 times, each $30 \mathrm{~s}$ at $4{ }^{\circ} \mathrm{C}$ and was subsequently centrifuged $20 \mathrm{~min}$ at $18,000 \mathrm{~g}$. Supernatant was collected and pellet was resuspended in initial volume using lysis buffer. Total fraction, supernatant and pellet were analyzed for the presence of soluble PrP by SDS/PAGE and immunoblotting.

\section{Growth curve and quantification of PrP production}

For plotting the growth curve of $\operatorname{MoPrP}(89-230)$ smallscale cultures (MoPrP/QSOX and MoPrP/no QSOX) were produced as described previously. Samples were collected at 30 minutes time intervals and $A_{600}$ was measured. Optical density was plotted versus time.
To quantify the amount of PrP produced at the different times during the growth, $1 \mathrm{~L}$ culture was induced as described earlier and $40 \mathrm{~mL}$ samples were collected at 0 , $1,2,4,8$ and $16 \mathrm{~h}$ after induction. Cells were collected by centrifugation at $15,000 \mathrm{~g}$ for $10 \mathrm{~min}$, weighted and resuspended in $(0.1 \mathrm{~g}$ of cell paste $/ \mathrm{mL})$ volume of lysis buffer to normalize the cell content for each time point. For estimating the total prion production $4 \mu \mathrm{l}$ were mixed with $1 \mu \mathrm{l}$ SDS loading buffer (5X) and boiled for 5 min. To determine the quantity of soluble expressed PrP, resuspended cells were lysed by sonication and centrifuged at 18,000 g for $20 \mathrm{~min}$. $4 \mu \mathrm{l}$ of supernatant was mixed with $1 \mu \mathrm{l}$ SDS loading buffer (5X) and boiled for 5 min. Collected samples were analyzed on SDS-PAGE and by immunoblotting. Intensity of the blot signals was quantified using the software LabImage 1D Gel Analysis (Kapelan GmbH, Germany).

\section{Immunoblotting}

Mouse monoclonal anti-His antibody was purchased from Sigma Aldrich, Belgium. Proteins analyzed on SDSPAGE were transferred to nitrocellulose membranes (MACHEREY-NAGEL) and bands were visualized by goat anti-mouse IgG, alkaline phosphatase conjugate (Sigma) using NBT/BCIP as substrate (Roche Diagnostics, GmbH, Germany).

\section{Large-scale protein expression and purification}

MoPrP(89-230), HuPrP(90-231), MoPrP(23-230) and HuPrP(23-231) were co-expressed with QSOX in E. coli Rossetta (DE3) pLysS. Expression up-scaling was carried out as follows. Pre-cultures $(25 \mathrm{~mL})$ were grown overnight at $37^{\circ} \mathrm{C}$ in $\mathrm{LB}$ medium supplemented with $100 \mu \mathrm{g} / \mathrm{mL}$ ampicillin and $25 \mu \mathrm{g} / \mathrm{mL}$ kanamycin. $10 \mathrm{~mL}$ of pre-culture were used to inoculate $1 \mathrm{~L}$ of LB medium supplemented with ampicillin and kanamycin. Cells were induced at $\mathrm{A}_{600}=0.7$ by adding $1 \mathrm{mM}$ isopropyl-b-D-thiogalactopyranoside (IPTG) and temperature was shifted to $15^{\circ} \mathrm{C}$ for $16 \mathrm{~h}$

Cells were harvested by centrifugation (15 min at 15,000 g). Cells pellets were re-suspended as $0.1 \mathrm{~g}$ of cell paste $/ \mathrm{mL}$ in $50 \mathrm{mM}$ potassium phosphate, $\mathrm{pH} 7.5,300 \mathrm{mM} \mathrm{NaCl}$ supplemented with $0.1 \mathrm{mg} / \mathrm{mL}$ lysozyme, $0.1 \mathrm{mg} / \mathrm{mL}$ AEBSF and $1 \mu \mathrm{g} / \mathrm{mL}$ leupeptin. Cells were disrupted two times with a French press $(10,000$ psi) and followed by centrifugation at $4^{\circ} \mathrm{C}$ for $60 \mathrm{~min}$ at 40,000 g. The collected supernatant was loaded on a $5 \mathrm{~mL}$ Histrap Ni-NTA column (GE-healthcare) previously equilibrated with $50 \mathrm{mM}$ potassium phosphate $\mathrm{pH}$ 7.5, $300 \mathrm{mM} \mathrm{NaCl}, 10 \mathrm{mM}$ imidazole. The column was washed with five column volumes (CV) of washing buffer: $50 \mathrm{mM}$ potassium phosphate $\mathrm{pH}$ 7.5, $1 \mathrm{M} \mathrm{NaCl}, 50 \mathrm{mM}$ imidazole, followed by ten $\mathrm{CV}$ of $50 \mathrm{mM}$ potassium phosphate $\mathrm{pH} 6.0,1 \mathrm{M} \mathrm{NaCl}, 50 \mathrm{mM}$ imidazole. The protein was eluted with a gradient of 
imidazole from $50 \mathrm{mM}$ to $1 \mathrm{M}$ in $50 \mathrm{mM}$ potassium phosphate $\mathrm{pH}$ 7.5. The elution peak fractions were loaded on a SDS/PAGE to evaluate purity, then pooled, and concentrated for a second purification step. Size exclusion chromatography was performed in $20 \mathrm{mM}$ Tris- $\mathrm{HCl} \mathrm{pH} 7.5$ with $150 \mathrm{mM} \mathrm{NaCl}$ on a Superdex75 HR 10/30 (GE Healthcare). The elution peak was again loaded on SDS/ PAGE and collected for a dialysis against $10 \mathrm{mM}$ sodium acetate $\mathrm{pH}$ 4.6, $1 \mathrm{mM}$ EDTA followed by the final dialysis buffer of $10 \mathrm{mM}$ sodium acetate $\mathrm{pH}$ 4.6. Protein aliquots were stored at $-80^{\circ} \mathrm{C}$ until further usage.

\section{Circular dichroism (CD) experiments}

$\mathrm{CD}$ spectra were recorded at $25^{\circ} \mathrm{C}$ using a spectropolarimeter (Jasco, model 715, Tokyo, Japan). The purified protein was diluted in water to the final concentration of $0.2 \mathrm{mg} / \mathrm{mL}$. CD spectra were acquired at a scan speed of $50 \mathrm{~nm} / \mathrm{min}, 1 \mathrm{~nm}$ bandwidth and a response time of $1 \mathrm{~s}$. A $0.01 \mathrm{~cm}$ path length quartz cells was used to record spectra of the different proteins in the far ultraviolet region (190-260 $\mathrm{nm}$ ), each spectrum was recorded 4 times. The sample and the buffer solutions were purged with dry nitrogen.

\section{Nuclear magnetic resonance (NMR) measurements} Uniformly ${ }^{15} \mathrm{~N}$ and both ${ }^{15} \mathrm{~N}$ and ${ }^{13} \mathrm{C}$-labeled $\operatorname{MoPrP}(89$ 230) were produced in M9 minimal medium supplemented with ${ }^{15} \mathrm{NH}_{4} \mathrm{Cl}$ and $\left[{ }^{13} \mathrm{C}\right]$ glucose as described by Marley et al. [17]. The labelled proteins were purified as described above for unlabelled proteins.

The NMR experiments were recorded on ${ }^{15} \mathrm{~N},{ }^{13} \mathrm{C}$ labeled MoPrP(89-230) concentrated to approximately $0.5 \mathrm{mM}$ into $10 \mathrm{mM}$ sodium acetate buffer $\mathrm{pH}$ 4.6. Two dimensional NMR ${ }^{15} \mathrm{~N}$ and ${ }^{13} \mathrm{C}$ heteronuclear single quantum correlation (HSQC) spectra and three dimensional NMR experiments CBCA(CO)NH, HNCACB, $\mathrm{HNCO}, \mathrm{HBHA}(\mathrm{CO}) \mathrm{NH}$ were performed at $293 \mathrm{~K}$ on MoPrP(89-230) on a Varian NMR Direct-Drive Systems $800 \mathrm{MHz}$ spectrometer equipped with a salt tolerance triple-resonance PFG-Z cold probe. Sequence specific backbone ${ }^{1} \mathrm{HN},{ }^{15} \mathrm{~N},{ }^{13} \mathrm{C},{ }^{13} \mathrm{C}^{\mathrm{a}},{ }^{13} \mathrm{C}^{\mathrm{b}}, \mathrm{H}^{\mathrm{a}}$ and $\mathrm{H}^{\mathrm{b}}$ chemical shifts were determined using standard triple-resonance assignment methodology [18]. Identical experiments were performed for $\operatorname{MoPrP}(89-230)$ at $\mathrm{pH}$ 7.0. All the NMR data were processed with NMRPipe 2.1 software [19] and analysed using CCPNmr Analysis 2.0 [20]. CS23D2.0 [21] was used to generate a 3D model of $\operatorname{MoPrP}(89-230)$ at $\mathrm{pH} 4.6$ using only the backbone chemical shifts.

\section{Thiostar assay}

The thiostar assay determines accurately the amount of free thiol content in samples [22]. To perform this assay, we used the kit Detect $\mathrm{X}^{\mathrm{TM}}$, Luminos (Arbor assays,
USA). A standard curve was plotted using reduced L-glutathion (Sigma, Belgium) at different concentrations $(0 \mu \mathrm{M}, 10 \mu \mathrm{M}, 20 \mu \mathrm{M}, 30 \mu \mathrm{M}, 40 \mu \mathrm{M}, 50 \mu \mathrm{M}$ and $60 \mu \mathrm{M})$. Two protein samples were tested: soluble $\operatorname{PrP}$ and refolded, both samples were tested at a fixed concentration of $5 \mu \mathrm{M}$. All standards and samples were diluted 10 times in a thiol-free buffer to a final volume of $100 \mu \mathrm{L}$ in a 96-well plate. Then we added $15 \mu \mathrm{L}$ of Thiostar reagent to each well. After mixing, we incubated the plate at room temperature for $30 \mathrm{~min}$ in the dark. The fluorescent product was measured at $510 \mathrm{~nm}$ in a fluorescent plate-reader (Infinite M200, TECAN) with excitation at $390 \mathrm{~nm}$

\section{Amyloid seeding assay (ASA) protocol}

MoPrP(89-230) has been diluted to $0.1 \mathrm{mg} / \mathrm{mL}$ in phosphate-buffered saline (PBS) solution containing $0.4 \mathrm{M}$ Guanidine hydrochloride (GuHCl), $10 \mathrm{mM}$ Thioflavin T (ThT). The fibrilization reaction was performed in a final volume of $200 \mu \mathrm{L}$ in 96-well plate (BD Falcon, BD Bioscience). For seeding experiment we performed the amyloid seeding assay (ASA) according to Colby et al., 2007 [23] with some minor modifications. Briefly, $1 \mathrm{mg}$ of ScGT1 cell lysate were used for PTA precipitation by adding $500 \mu \mathrm{L}$ of PBS containing 4\% sarkosyl, protease inhibitor (Complete, Roche) and $0.5 \%$ PTA, with continuous shaking at $37^{\circ} \mathrm{C}, 350 \mathrm{rpm}$ for $1 \mathrm{~h}$ and centrifuged $14,000 \mathrm{~g}$ for $30 \mathrm{~min}$. The pellet was washed and resuspended in the previous buffer, then centrifuged again and re-suspended in $150 \mu \mathrm{L}$ of sterile double distilled $\mathrm{H}_{2} \mathrm{O}$. In ASA, $4 \mu \mathrm{L}$ of re-suspended PTA pellet were diluted in $400 \mu \mathrm{L}$ of water and $20 \mu \mathrm{L}$ of diluted sample were added to each well. The plate was incubated at $37^{\circ} \mathrm{C}$ with continuous shaking on a plate reader (Spectramax M5, Molecular Device). The kinetics of fibril formation was monitored by top reading of fluorescence intensity every $5 \mathrm{~min}$ at $444 \mathrm{~nm}$ excitation and $485 \mathrm{~nm}$ emission.

\section{Conversion of the monomeric MoPrP into amyloid fibrils} MoPrP(89-230) was diluted into $50 \mathrm{mM}$ phosphate buffer, $2 \mathrm{M} \mathrm{GuHCl}, \mathrm{pH} 6.5$ to a final concentration of $0.4 \mathrm{mg} / \mathrm{ml}$ and incubated at $37^{\circ} \mathrm{C}$ with constant rotation (8 rpm).

\section{Atomic Force Microscopy (AFM)}

The converted PrP samples were incubated on a freshly cleaved mica surface for approximately 30 seconds and subsequently rinsed with water to remove salts and unbound protein. After drying the samples were imaged using tapping mode on a Digital Instruments Multimode atomic force microscope equipped with Nanoscope IV controller and a type E scanner. All images were acquired using single-beam silicon probes with a nominal spring constant of $40 \mathrm{~N} / \mathrm{m}$ and nominal tip radius of $10 \mathrm{~nm}$. 


\section{X-ray fiber diffraction}

Converted PrP was pelleted by centrifugation at 16,000 g, and pellet was subsequently washed twice with water to remove salts. The wet pelleted fibrils were pipetted in a $2 \mathrm{~mm}$ space between two fire-polished glass rods and allowed to dry. Diffraction patterns were collected using a Rigaku MicroMax-007HF copper anode X-ray source and a Rigaku Saturn 944+ CCD detector.

\section{Results and discussion}

Two set of constructs for each species were used to evaluate the effect of QSOX co-expression in increasing the solubility of PrP: full-length MoPrP(23-230), HuPrP(23231), truncated $\operatorname{MoPrP}(89-230)$ and $\operatorname{HuPrP}(90-231)$. The constructs were cloned into pET28a plasmid, while the QSOX gene was expressed in a pTRC-HisA vector. Both plasmids are IPTG inducible for simultaneous expression of both proteins. We evaluated the expression level and solubility of each construct on SDS-PAGE and immunoblot with anti-His-tag antibody (Figure 1). In addition, we examined protein expression and solubility of $\operatorname{MoPrP}(89-$ 230 ) in the presence and absence of QSOX at various time points after induction in standard LB broth. After induction, cells expressing both proteins showed a reduced growth rate compared to the one expressing only MoPrP (89-230) (Figure 2A), which is probably an effect of the metabolic burden imposed by the double recombinant proteins over-expression [24]. Immunoblot analysis using anti-His-tag specific antibodies on total cell extracts showed that the total production of $\operatorname{MoPrP}(89-230)$ during the first three hours of the induction is equivalent between cells with or without QSOX. However, after three hours of induction a difference in total PrP production between both cells is observed. In cells without QSOX, the total concentration of PrP decreased compared to cells with QSOX, where the PrP concentration remained constant over time (Figure 2B, C, D). Expression of PrP without QSOX is known to produce insoluble recombinant protein [8], hence the decrease in PrP concentration could be attributed to the degradation of the insoluble fraction by cytoplasmic proteases [25]. We further estimated the quantity of soluble $\operatorname{MoPrP}(89-230)$ during the course of the induction (Figure 2E, F). In absence of QSOX, no soluble PrP is present in the cell extracts throughout the 16 hours of induction, while in presence of QSOX, soluble PrP can be detected after two hours induction. The

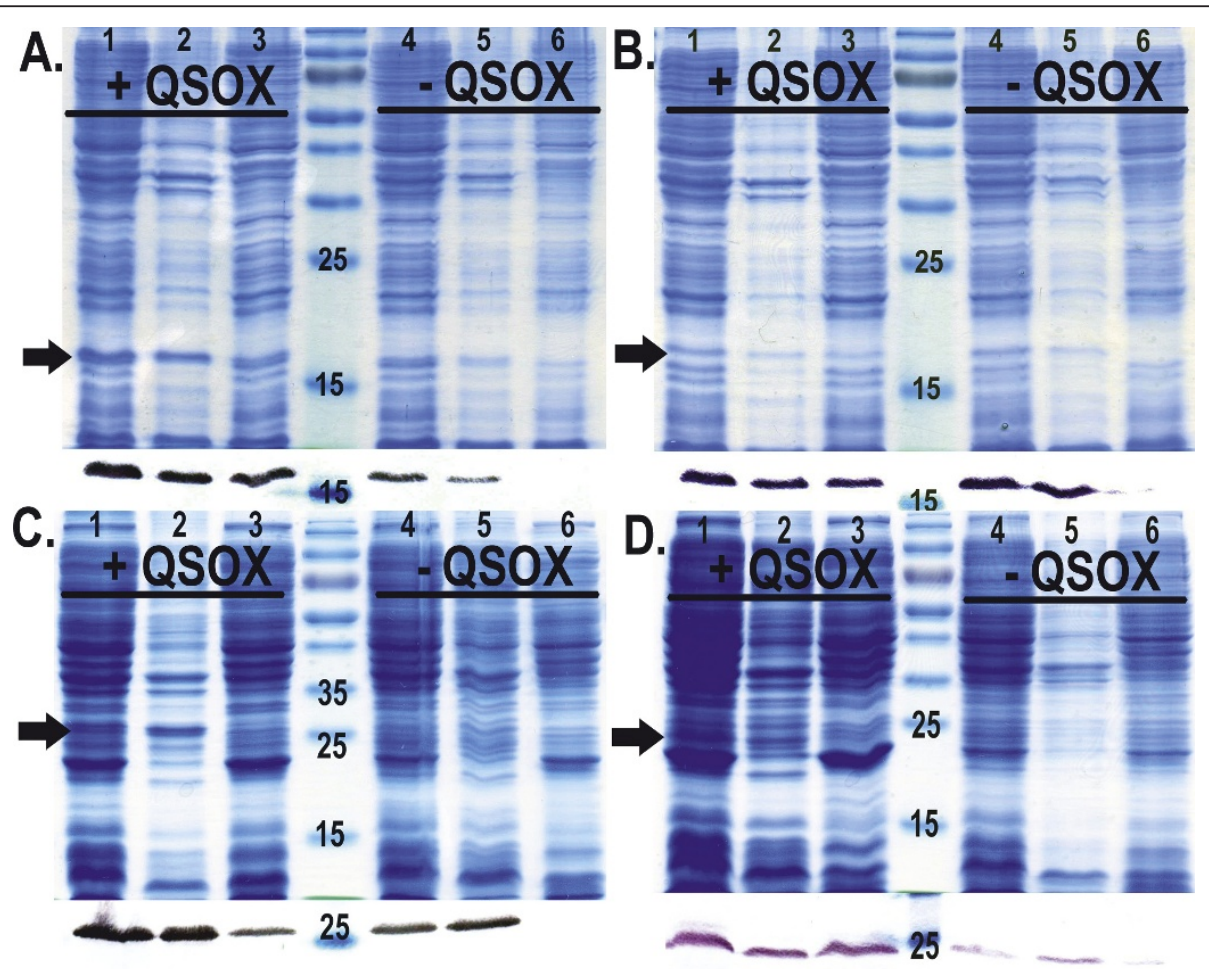

Figure 1 Effect of the co-expression of QSOX on the expression of soluble PrP in the cytoplasm of E. coli. A) SDS-PAGE analysis of MoPrP (89-230). Expression trials in presence of QSOX: Lane $1=$ total $E$. coli lysate, Lane $2=$ insoluble fraction, Lane $3=$ soluble fraction. Expression trials in absence of QSOX: Lane 4 = total $E$. coli lysate, Lane 5 = insoluble fraction, Lane 6 = soluble fraction. The black arrow indicates the MoPrP(89-230). The corresponding immunoblot using anti-His-tag antibody is shown underneath the SDS-PAGE gel. B) SDS-PAGE and immunoblot analysis of HuPrP(90-231). C) SDS-PAGE and immunoblot analysis of MoPrP(23-230). D) SDS-PAGE and immunoblot analysis of HuPrP(23-231). 

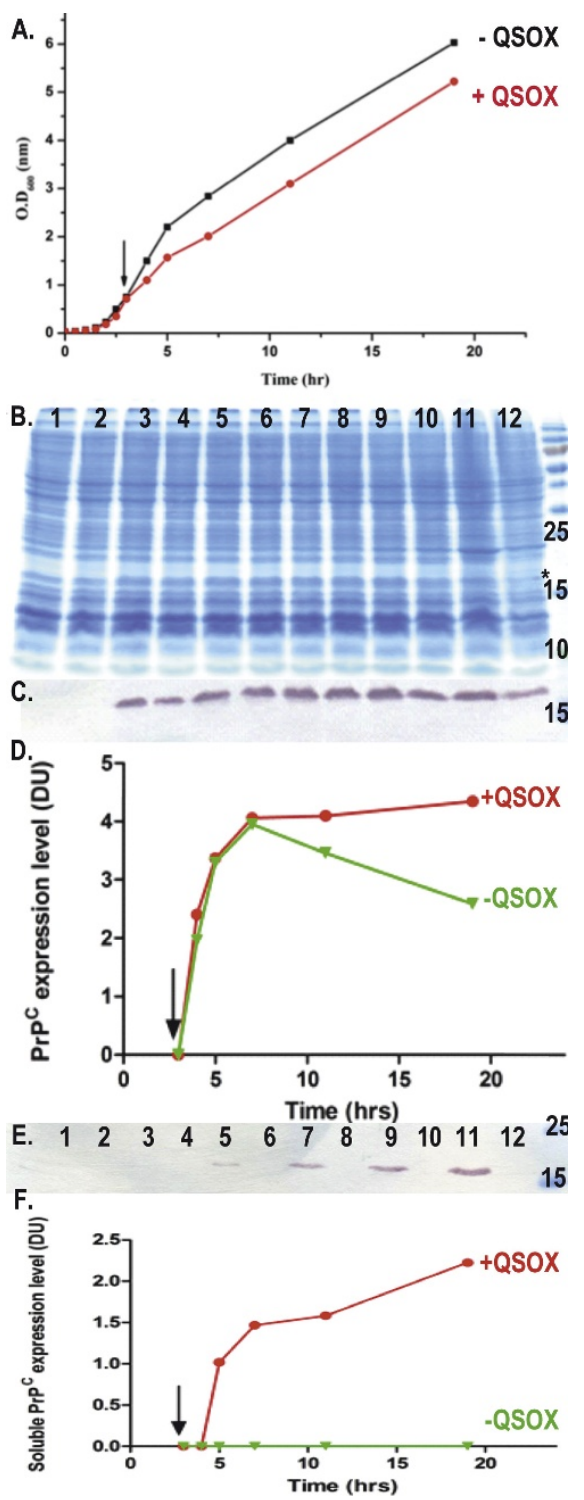

Figure 2 Production of $\operatorname{MoPrP}(89-230)$ in E. coli. A) Growth curve of $E$. coli cells, showing the expression of $\operatorname{MoPrP}(89-230)$ : absence of QSOX and co-expressed with QSOX in black and in red respectively. B) SDS-PAGE of total cell extract. Lane 1: (+) QSOX before induction, lane 2: (-) QSOX before induction, 3: (+) QSOX $1 \mathrm{~h}$ after induction, lane 4: (-) QSOX $1 \mathrm{~h}$ after induction, lane 5: (+) QSOX $2 \mathrm{~h}$ after induction, lane 6: (-) QSOX $2 \mathrm{~h}$ after induction, lane 7: (+) QSOX $4 \mathrm{~h}$ after induction, lane 8: (-) QSOX $4 \mathrm{~h}$ after induction, lane 9: (+) QSOX $8 \mathrm{~h}$ after induction, lane 10: (-) QSOX $8 \mathrm{~h}$ after induction, lane 11: (+) QSOX $16 \mathrm{~h}$ after induction, lane 12: (-) QSOX $16 \mathrm{~h}$ after induction and lane 13: MW. C) Immunoblot showing the expression level of total MoPrP(89-230) over time. D) Quantification of the total production of MoPrP(89-230) expressed over $16 \mathrm{~h}$. Intensities from the western blot signal were quantified using the Lablmage software, in presence of QSOX and in absence of QSOX in red and green respectively. E) Immunoblot showing the expression level of soluble MoPrP(89-230) over time (same time points as in B). F)

Quantification of the production of soluble MoPrP(89-230) expressed over $16 \mathrm{~h}$, in presence of QSOX and in absence of QSOX in red and green respectively. quantity of $\mathrm{PrP}$ in the soluble fraction increased until it reached a plateau after 16 hours of induction. The soluble recombinant $\operatorname{PrP}$ has been purified by Immobilized Metal Affinity Chromatography (IMAC), followed by a size exclusion chromatography to high purity (Figure 3). The yields per litre of culture after purification were $1 \mathrm{mg} / \mathrm{L}$ for $\operatorname{MoPrP}(23-230)$ and $9 \mathrm{mg} / \mathrm{L}$ for $\operatorname{MoPrP}(89-230)$. For the human PrP, the yield was $1.5 \mathrm{mg} / \mathrm{L}$ for $\operatorname{HuPrP}(23-231)$ and $3 \mathrm{mg} / \mathrm{L}$ for $\mathrm{HuPrP}(90-231)$. Attempts to produce soluble PrP with commercially available chaperones like DnaK, DnaJ, GrpE, GroES, GroEL failed (data not shown).

In the next step, we evaluated the structure of the different PrP construct co-expressed with QSOX with far-UV circular dichroism $(C D)$ and nuclear magnetic resonance (NMR) spectroscopy. All CD spectra show a double minimum at 208 and $222 \mathrm{~nm}$, characteristic for $\alpha$-helical proteins, indicating that all four $\operatorname{PrP}$ contain a significant amount of secondary structure (Figure 4A). Moreover, the 1D ${ }^{1} \mathrm{H}$ NMR spectra showed that all soluble expressed PrP are well folded (Figure 4B). Previous studies on PrP showed that the presence of a disulfide bond is essential to maintain the $\alpha$-helical fold of the C-terminal end [12]. Therefore, we verified whether the disulfide is formed in soluble expressed PrP using a Thiostar assay [22] (Figure 5). No free thiols were found in soluble expressed PrP, confirming that a disulfide bond is indeed formed upon expression in the cytoplasm.

In order to explore in detail the structure of the soluble mouse PrP, uniformly ${ }^{15} \mathrm{~N}-{ }^{13} \mathrm{C}$-labelled $\operatorname{MoPrP}(89-230)$ was produced in co-expression with QSOX. ${ }^{1} \mathrm{H}_{-}{ }^{15} \mathrm{~N}$ HSQC spectra are characteristic for a well-folded protein with no tendency for aggregation at both $\mathrm{pH} 4.6$ and $\mathrm{pH}$ 7.0 (Figure 6A). Backbone assignments at $\mathrm{pH} 4.6$ are essentially complete $(\approx 96 \%)$, except for the ten N-terminal residues that include the hexahistidine tag. Most importantly, the $C \beta$ chemical shifts of Cys179 and Cys214 are indicative for a disulfide bond between the two cysteines, concurring with the Thiostar assay. The consensus chemical shift index (CSI) [26] indicates the presence of three $\alpha$-helices (144-154), (177-193), and (200-227). The CSI also suggests that regions (128-131) and (160-164) show some propensity for $\beta$-strand conformation (Figure 6B). A preliminary three-dimensional model of $\operatorname{MoPrP}(89-230)$ was generated from the ${ }^{1} \mathrm{H}$, ${ }^{13} \mathrm{C}$, and ${ }^{15} \mathrm{~N}$ backbone chemical shifts using CS23D2.0 [21]. The resulting three-dimensional model exhibits mainly an $\alpha$-helical structure with three $\alpha$-helices displaying an orientation similar to the previous structure of $\operatorname{MoPrP}(121-231)$ [27]. Alignment of the two structures suggests that $\alpha 2$ and $\alpha 3$ helices in our model are slightly more elongated (Figure 7). Interestingly, $\alpha 3$ in our model forms a regular $\alpha$-helix from E200 to G227, with no break between Q219 and S222 as observed in the NMR structure of the refolded $\operatorname{MoPrP}(121-231)$ [27]. ${ }^{1} \mathrm{H}_{-}{ }^{15} \mathrm{~N}$ 


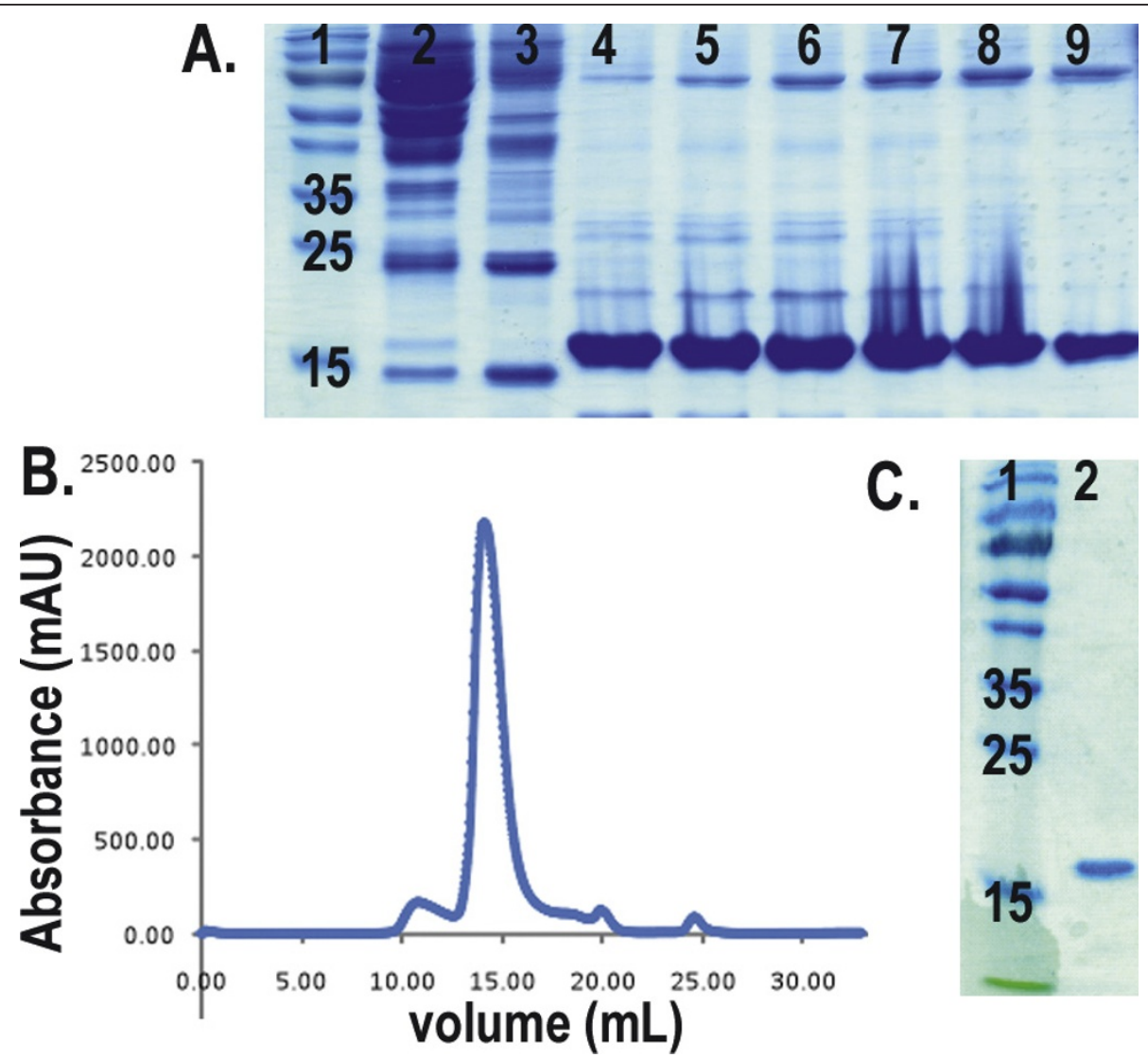

Figure 3 Purification of soluble MoPrP(89-230). A) Purification of MoPrP(89-230) after Ni-NTA. Lane 1: Molecular weight. Lane 2: Lysate (soluble fraction). Lane 3: Flow through. Lane 4 to 9: Elution peak. B) Size exclusion chromatogram (Superdex75 HR10/30). C) SDS/PAGE of pooled fractions from the highest elution peak (from 13 to $16 \mathrm{~mL}$ elution volume). Lane 1: Molecular weight. Lane 2: pooled fractions contain purified PrP.

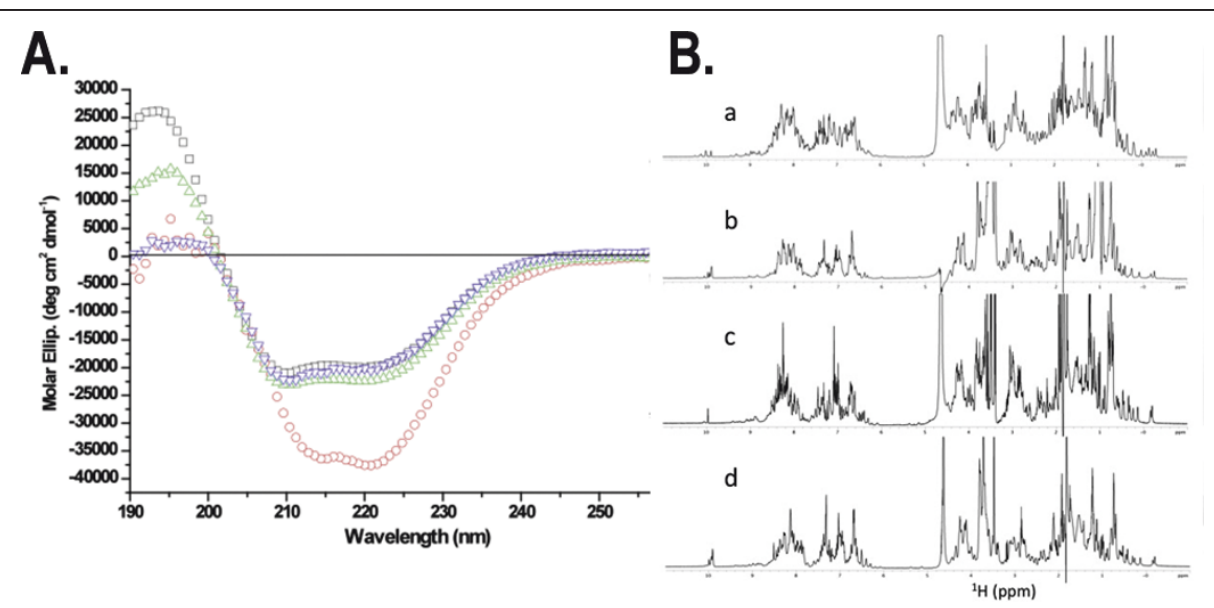

Figure 4 Biophysical characterisation of the four soluble PrP. A) Far-UV CD spectra of the four soluble PrP collected at $25^{\circ} \mathrm{C}$ in sodium acetate buffer $\mathrm{pH}$ 4.6. MoPrP(23-230) in red, $\operatorname{HuPrP}(23-231)$ in blue, MoPrP(89-230) in black and $\operatorname{HuPrP}(90-231)$ in green. B) $1 \mathrm{D} 800 \mathrm{MHz}{ }^{1} \mathrm{H}$ NMR spectra of the soluble PrP: (a) MoPrP(89-230), (b) MoPrP(23-230), (c) HuPrP(90-231) and (d) HuPrP(23-231). All spectra were recorded at $25^{\circ} \mathrm{C}, \mathrm{pH}$ 4.6. 


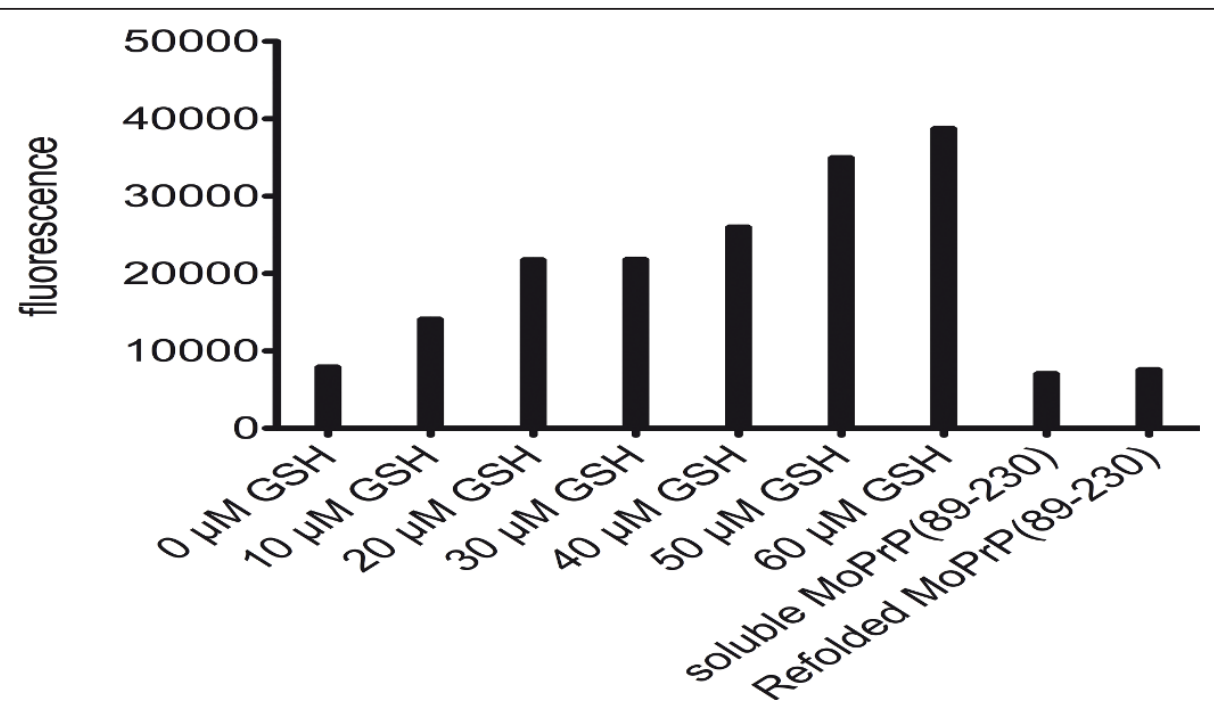

Figure 5 Thiostar assay for soluble and refolded MoPrP(89-230). Fluorescence of free thiols in soluble and refolded $\operatorname{PrP}(5 \mu \mathrm{M})$ compared to reduced L-glutathione $(0 \mu \mathrm{M}, 10 \mu \mathrm{M}, 20 \mu \mathrm{M}, 30 \mu \mathrm{M}, 40 \mu \mathrm{M}, 50 \mu \mathrm{M}$ and $60 \mu \mathrm{M})$.

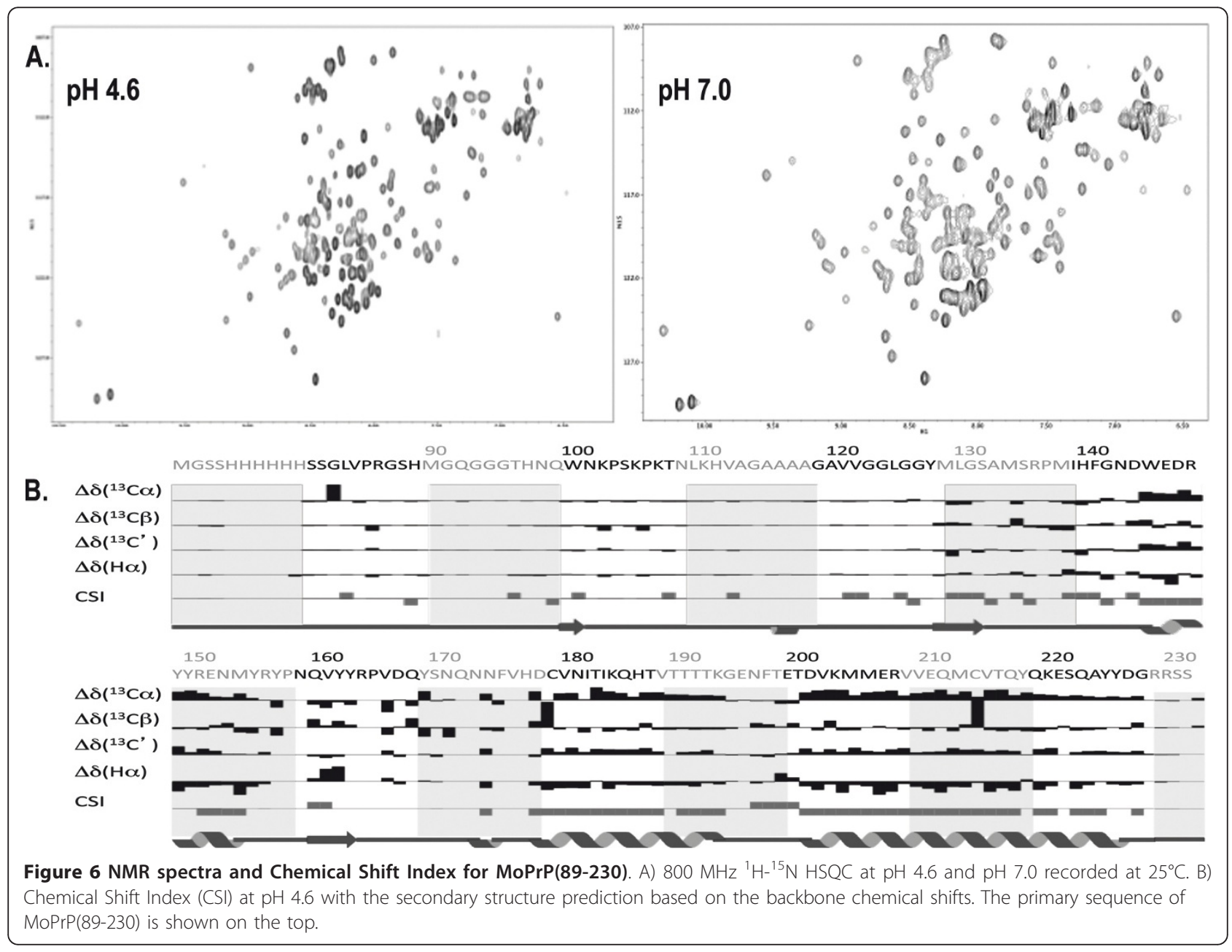




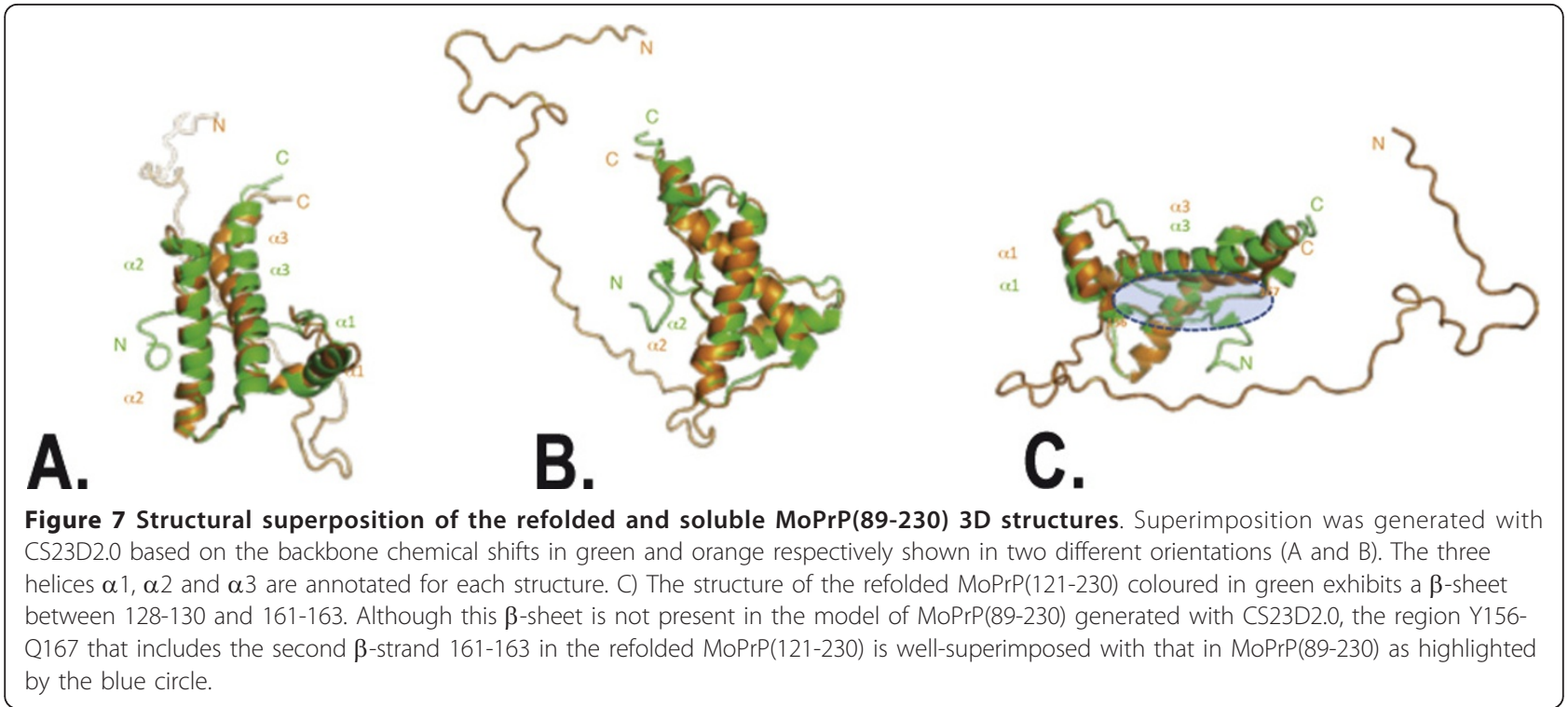

heteronuclear NOEs measured in $\operatorname{MoPrP}(89-230)$ show no significant variations within the (200-227) region with an average value of 0.8 indicative of restricted motions along the $\alpha 3$ helix (Figure 8 ). The structure of the refolded $\operatorname{MoPrP}(121-231)$ exhibits a $\beta$-sheet between 128 to 130 and from 161 to 163 [27]. Although this $\beta$-sheet is not proposed in the model of $\operatorname{MoPrP}(89-230)$ generated with CS23D2.0, manual analysis of ${ }^{15} \mathrm{~N}$-NOESY-HSQC and ${ }^{13} \mathrm{C}$-NOESY-HSQC spectra allowed the identification of specific long range $\mathrm{NH}-\mathrm{NH}$ and $\mathrm{CH}^{\alpha}-\mathrm{CH}^{\alpha}$ NOEs between the residues 127 to 130 and 161 to 164 (data not shown) supporting the formation of the antiparallel $\beta$ sheet present in the soluble $\operatorname{MoPrP}(89-230)$ protein.

We have also tested if the soluble $\operatorname{MoPrP}(89-230)$ can form fibrils. It is commonly accepted in the prion biology field that $\operatorname{PrP}$ amyloid fibrils generated in vitro can be used as a synthetic surrogate for $\operatorname{PrP}^{\mathrm{Sc}}$ [23]. We generated in vitro the amyloid aggregates using the soluble $\operatorname{MoPrP}(89-230)$ because this truncated MoPrP has been extensively studied in fibrils studies [23]. To generate in vitro fibrils we used the amyloid seeding assay (ASA) protocol, which is a high-throughput technique for prion fibrils formation in vitro developed in the Prusiner laboratory. The fibrilization reaction was performed in quasi-native condition at physiological $\mathrm{pH}$ and in the presence of a low concentration of denaturant (0.4 M $\mathrm{GuHCl})$. The polymerization process was monitored simply by applying thioflavin $\mathrm{T}$ in the reaction mixture. This dye shows strong increase of fluorescence upon binding to $\beta$-sheet rich structures like amyloid aggregates. When

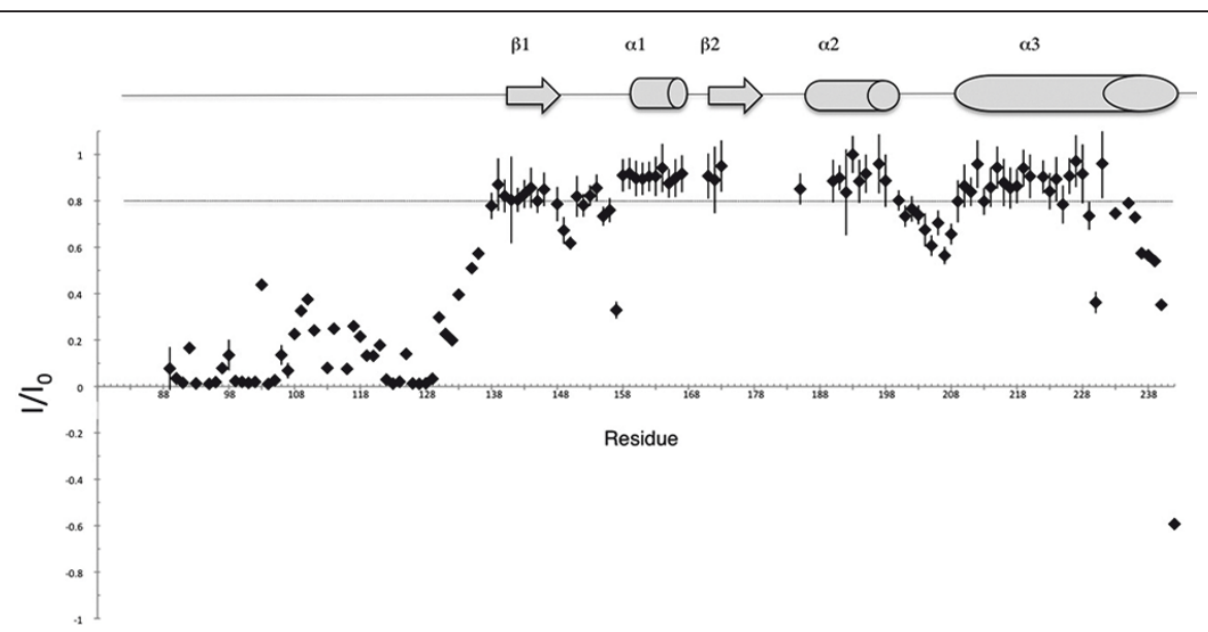

Figure 8 Plots of the ${ }^{1} \mathrm{H}^{-15} \mathrm{~N}$ NOEs versus the residue numbers of MoPrP(89-230). A schematic of the secondary structure of MoPrP(89-230) is shown above the graph. 
used in conjunction with multi-well plates and automated fluorescence plate readers, the ThT represents a feasible, highly sensitive, high-throughput approach for the detection of conformational changes of proteins. In our experiments we observed a strong increase in fluorescence, which corresponds to the ThT binding to $\beta$ sheet rich structures like amyloid aggregates (Figure 9). Our results are consistent with previous fibrilization experiments performed with $\operatorname{MoPrP}(89-230)$ expressed in E. coli as inclusion bodies [28,29] and provide a good indication about the ability of soluble $\operatorname{MoPrP}(89-230)$ to form ThT-positive fibrils. Furthermore, to gain insight into the morphology and structure of amyloid fibrils formed using solubly expressed $\operatorname{MoPrP}(89-230)$ we performed atomic force microscopy and X-ray fibril diffraction (Figure 10). The observed fibrils were hundreds of nanometers in length and had a measured height and width of approximately $5 \mathrm{~nm}$. Their diffraction pattern shows reflections at $4.7 \AA$ and $\sim 10 \AA$, characteristic of the cross- $\beta$ pattern previously observed for fibrils formed by refolded recombinant PrP90-231 [30] and as well as other amyloidogenic proteins [31].

\section{Conclusion}

The formation of the disulfide bond between Cys179 and Cys214 is essential to obtain a correctly folded PrP $[12,32]$.

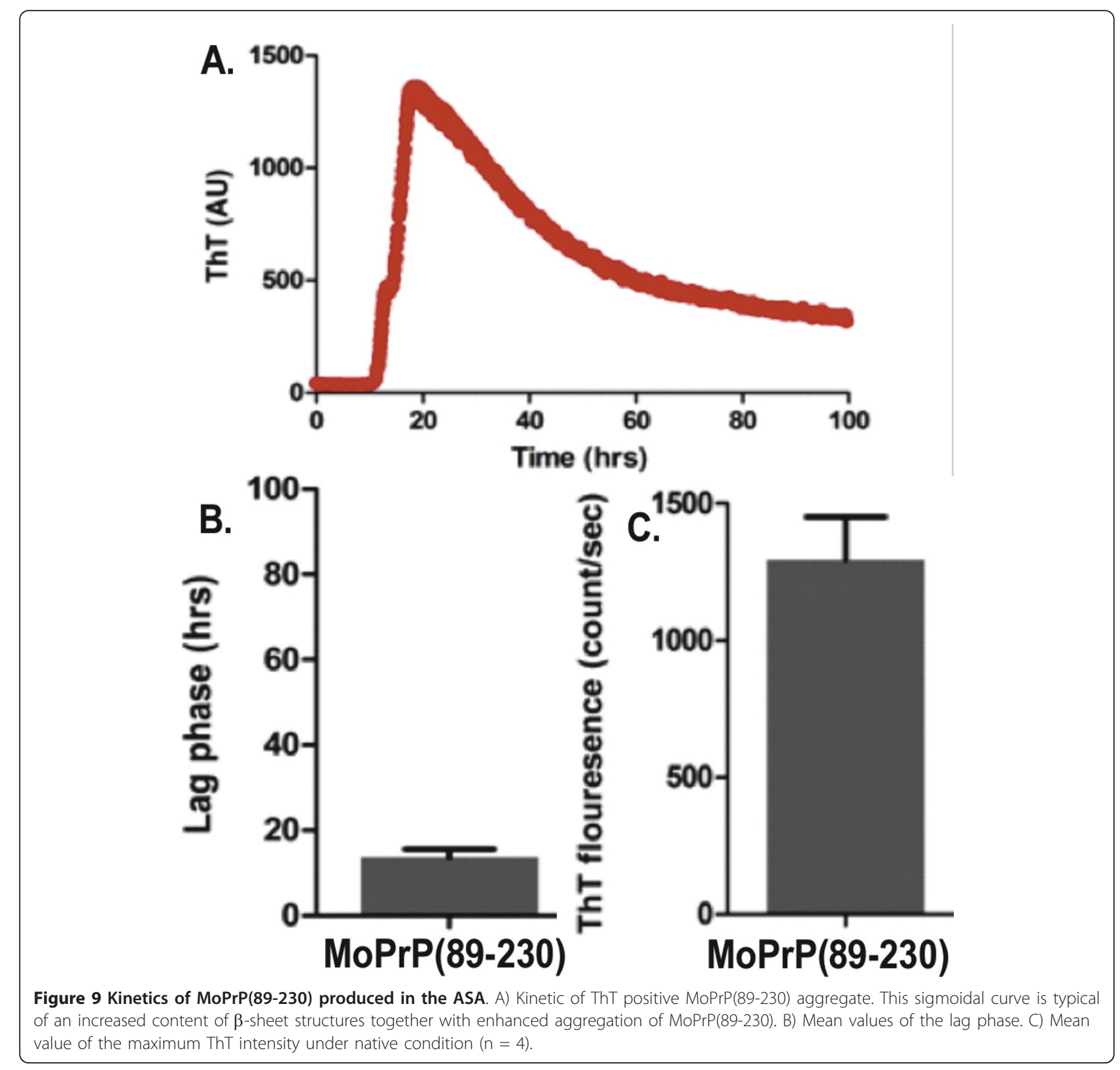



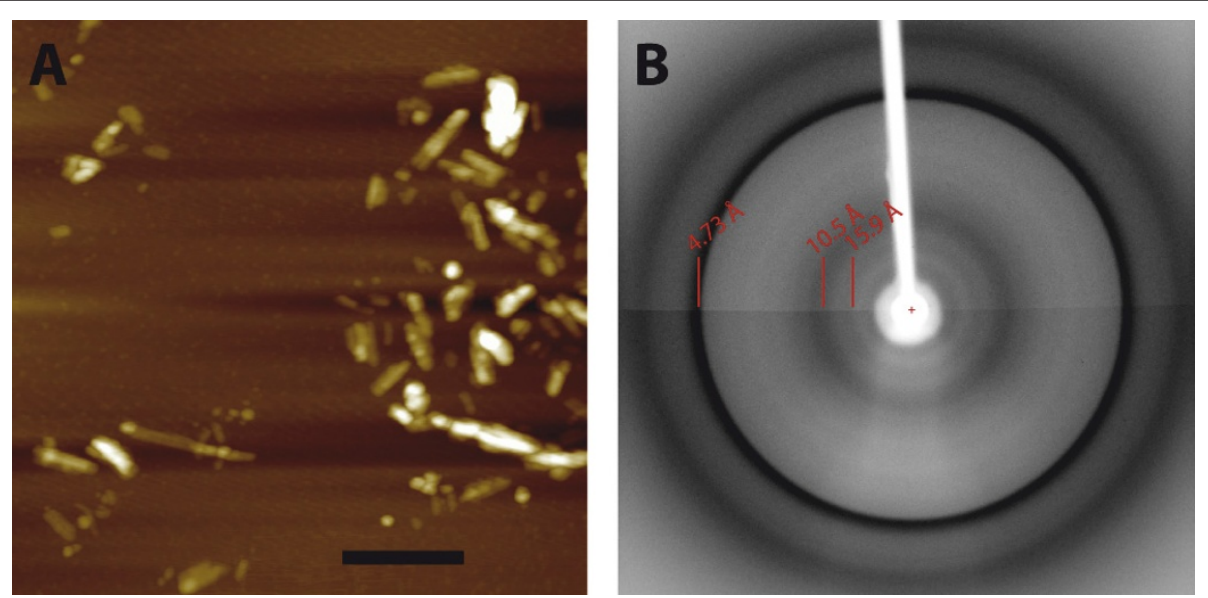

Figure 10 MoPrP(89-230) fibrils characterisation. A) Atomic force microscopy images of MoPrP(89-230) amyloid fibrils. The scale bars correspond to $200 \mathrm{~nm}$. B) X-ray fiber diffraction showing prominent sharp reflection at $4.73 \AA$ and diffuse reflection at $10.5 \AA$.

The human Quiescin Sulfhydryl OXidase (QSOX) allows the formation of native disulfide bonds in eukaryotic proteins expressed in the cytoplasm of E. coli $[14,33]$. We showed that co-expressing $\operatorname{PrP}$ (full-length or truncate $\mathrm{MoPrP}$ and $\mathrm{HuPrP}$ ) with QSOX produces a significant amount of correctly folded PrP in the cytoplasm and that a disulfide bond is present in the purified protein. Previous studies showed that co-expression with several chaperones did not succeed in producing reasonable quantities of soluble $\operatorname{PrP}$ [8]. Furthermore, soluble but partially degraded PrP could only be produced in the periplasm [9]. In $E$. coli, disulfide bond formation occurs in the periplasm [34]. Co-expression with QSOX is a good alternative to produce mammalian proteins containing disulfide bonds in the E. coli.

To the best of our knowledge, there is no evidence for direct interaction in vivo of QSOX with the PrP; therefore we believe that QSOX could be used to express different mammalian PrP in E. coli. The described method is a simple and effective method for producing large quantities of soluble PrP in E. coli, which can subsequently be used for functional and structural studies.

\section{Acknowledgements}

The plasmid containing the human QSOX gene was kindly provided by Prof. Colin Thorpe (University of Delaware). JM is a group leader of the VIB. We would like to thank Prof. Nico van Nuland for NMR assistance.

RNNA is supported by the European student exchange program "Erasmus Mundus ECW II" reference number (132878-EM-1-2007-BE-ERA Mundus-ECW). WG is supported by the European student exchange program "Erasmus Mundus ECW II" reference (141085-EM-1-2008-BE-ERA Mundus-ECW).

\section{Author details}

${ }^{1}$ VIB, Department of Structural Biology, Brussels, Belgium. ${ }^{2}$ Structural Biology Brussels, Vrije Universiteit Brussel, Belgium. ${ }^{3}$ Brussels Center for Redox Biology, Brussels, Belgium. ${ }^{4}$ Department of Biochemistry and Molecular Biology, Faculty of Pharmacy Helwan University, Cairo, Egypt. ${ }^{5}$ Laboratory of Prion Biology, Neurobiology Sector, Scuola Internazionale Superiore di Studi Avanzati (SISSA), via Bonomea 265, Trieste, Italy. ${ }^{6}$ Italian Institute of
Technology, SISSA Unit, via Bonomea 265, I-34136 Trieste, Italy. ${ }^{7}$ ELETTRA Laboratory, Sincrotrone Trieste S.C.p.A., I-34149 Basovizza, Trieste, Italy.

${ }^{8}$ Department of Physiology and Biophysics, Case Western Reserve University, Cleveland, Ohio 44106, USA.

\section{Authors' contributions}

RA, HH, WG, SR, GG and MA performed the experiments. AW prepared the graphic files. JM, SS, GL, JS and AW conceived and designed the experimental approach. AW coordinated the whole study. SR, SS, JM, AW prepared the manuscript. RA, HH cloned, expressed and purified the recombinant PrPs. SR performed NMR. WG performed the thiostar assay. GG performed ASA assay. MA performed AFM and fiber diffraction. All authors read and approved the final manuscript.

\section{Competing interests}

The authors declare that they have no competing interest

Received: 22 July 2011 Accepted: 10 January 2012

Published: 10 January 2012

\section{References}

1. Colby DW, Prusiner SB: Prions. Cold Spring Harb Perspect Biol 2011, 3(1): a006833.

2. Prusiner SB: Novel proteinaceous infectious particles cause scrapie. Science 1982, 216(4542):136-144.

3. Watts JC, Balachandran A, Westaway D: The expanding universe of prion diseases. PLoS Pathog 2006, 2(3):e26.

4. Soto C: Prion hypothesis: the end of the controversy? Trends Biochem Sci 2011, 36(3):151-158.

5. Makrides SC: Strategies for achieving high-level expression of genes in Escherichia coli. Microbiol Rev 1996, 60(3):512-538.

6. Baneyx F, Mujacic M: Recombinant protein folding and misfolding in Escherichia coli. Nat Biotechnol 2004, 22(11):1399-1408.

7. Mehlhorn I, Groth D, Stockel J, Moffat B, Reilly D, Yansura D, Willett WS, Baldwin M, Fletterick R, Cohen FE, et al: High-level expression and characterization of a purified 142-residue polypeptide of the prion protein. Biochemistry 1996, 35(17):5528-5537.

8. Kyratsous CA, Silverstein SJ, DeLong CR, Panagiotidis CA: Chaperone-fusion expression plasmid vectors for improved solubility of recombinant proteins in Escherichia coli. Gene 2009, 440:(1-2):9-15.

9. Hornemann S, Glockshuber R: Autonomous and reversible folding of a soluble amino-terminally truncated segment of the mouse prion protein. Journal of molecular biology 1996, 261(5):614-619.

10. Watts JC, Huo H, Bai Y, Ehsani S, Jeon AH, Shi T, Daude N, Lau A, Young R, $\mathrm{Xu} L$, et al: Interactome analyses identify ties of PrP and its mammalian paralogs to oligomannosidic N-glycans and endoplasmic reticulumderived chaperones. PLoS Pathog 2009, 5(10):e1000608. 
11. Hetz C, Russelakis-Carneiro M, Walchli S, Carboni S, Vial-Knecht E, Maundrell K, Castilla J, Soto C: The disulfide isomerase Grp58 is a protective factor against prion neurotoxicity. J Neurosci 2005, 25(11):2793-2802.

12. Maiti NR, Surewicz WK: The role of disulfide bridge in the folding and stability of the recombinant human prion protein. J Biol Chem 2001, 276(4):2427-2431.

13. Heckler EJ, Alon A, Fass D, Thorpe C: Human quiescin-sulfhydryl oxidase, QSOX1: probing internal redox steps by mutagenesis. Biochemistry 2008, 47(17):4955-4963.

14. Nguyen VD, Hatahet F, Salo KE, Enlund E, Zhang C, Ruddock LW: Preexpression of a sulfhydryl oxidase significantly increases the yields of eukaryotic disulfide bond containing proteins expressed in the cytoplasm of E.coli. Microbial cell factories 2011, 10:1.

15. Abskharon RN, Soror SH, Pardon E, El Hassan H, Legname G, Steyaert J, Wohlkonig A: Combining in-situ proteolysis and microseed matrix screening to promote crystallization of PrPc-nanobody complexes. Protein Eng Des Sel 2011, 24(9):737-741.

16. Kosmac M, Koren S, Giachin G, Stoilova T, Gennaro R, Legname G, Serbec VC: Epitope mapping of a $\operatorname{PrP}(\mathrm{Sc})$-specific monoclonal antibody: identification of a novel C-terminally truncated prion fragment. $\mathrm{Mol}$ Immunol 2011, 48(5):746-750.

17. Marley J, Lu M, Bracken C: A method for efficient isotopic labeling of recombinant proteins. J Biomol NMR 2001, 20(1):71-75.

18. Bottomley MJ, Macias MJ, Liu Z, Sattler M: A novel NMR experiment for the sequential assignment of proline residues and proline stretches in 13C/15N-labeled proteins. J Biomol NMR 1999, 13(4):381-385.

19. Delaglio F, Grzesiek S, Vuister GW, Zhu G, Pfeifer J, Bax A: NMRPipe: a multidimensional spectral processing system based on UNIX pipes. J Biomol NMR 1995, 6(3):277-293.

20. Vranken WF, Boucher W, Stevens TJ, Fogh RH, Pajon A, Llinas M, Ulrich EL, Markley JL, lonides J, Laue ED: The CCPN data model for NMR spectroscopy: development of a software pipeline. Proteins 2005, 59(4):687-696

21. Wishart DS, Arndt D, Berjanskii M, Tang P, Zhou J, Lin G: CS23D: a web server for rapid protein structure generation using NMR chemical shifts and sequence data. Nucleic Acids Res 2008, 36 Web Server: W496-502.

22. Park S, Lippard SJ: Redox state-dependent interaction of HMGB1 and cisplatin-modified DNA. Biochemistry 2011, 50(13):2567-2574.

23. Colby DW, Zhang Q, Wang S, Groth D, Legname G, Riesner D, Prusiner SB: Prion detection by an amyloid seeding assay. Proc Natl Acad Sci USA 2007, 104(52):20914-20919.

24. Flores S, de Anda-Herrera R, Gosset G, Bolivar FG: Growth-rate recovery of Escherichia coli cultures carrying a multicopy plasmid, by engineering of the pentose-phosphate pathway. Biotechnol Bioeng 2004, 87(4):485-494.

25. Gatti-Lafranconi P, Natalello A, Ami D, Doglia SM, Lotti M: Concepts and tools to exploit the potential of bacterial inclusion bodies in protein science and biotechnology. FEBS J 2011, 278(14):2408-2418.

26. Wishart DS, Sykes BD: The $13 \mathrm{C}$ chemical-shift index: a simple method for the identification of protein secondary structure using $13 \mathrm{C}$ chemicalshift data. J Biomol NMR 1994, 4(2):171-180.

27. Riek R, Wider G, Billeter M, Hornemann S, Glockshuber R, Wuthrich K: Prion protein NMR structure and familial human spongiform encephalopathies. Proc Natl Acad Sci USA 1998, 95(20):11667-11672.

28. Polano M, Bek A, Benetti F, Lazzarino M, Legname G: Structural insights into alternate aggregated prion protein forms. Journal of molecular biology 2009, 393(5):1033-1042.

29. Ai Tran HN, Sousa F, Moda F, Mandal S, Chanana M, Vimercati C, Morbin M, Krol S, Tagliavini F, Legname G: A novel class of potential prion drugs: preliminary in vitro and in vivo data for multilayer coated gold nanoparticles. Nanoscale 2010, 2(12):2724-2732.

30. Wille H, Bian W, McDonald M, Kendall A, Colby DW, Bloch L, Ollesch J, Borovinskiy AL, Cohen FE, Prusiner SB, et al: Natural and synthetic prion structure from X-ray fiber diffraction. Proc Natl Acad Sci USA 2009, 106(40):16990-16995

31. Sunde M, Serpell LC, Bartlam M, Fraser PE, Pepys MB, Blake CC: Common core structure of amyloid fibrils by synchrotron X-ray diffraction. Journal of molecular biology 1997, 273(3):729-739.

32. Welker E, Wedemeyer WJ, Narayan M, Scheraga HA: Coupling of conformational folding and disulfide-bond reactions in oxidative folding of proteins. Biochemistry 2001, 40(31):9059-9064.
33. Thorpe C, Coppock DL: Generating disulfides in multicellular organisms: emerging roles for a new flavoprotein family. J Biol Chem 2007, 282(19):13929-13933.

34. de Marco A: Strategies for successful recombinant expression of disulfide bond-dependent proteins in Escherichia coli. Microbial cell factories 2009, $8: 26$.

doi:10.1186/1475-2859-11-6

Cite this article as: Abskharon et al: A novel expression system for production of soluble prion proteins in E. coli. Microbial Cell Factories 2012 11:6

\section{Submit your next manuscript to BioMed Central and take full advantage of:}

- Convenient online submission

- Thorough peer review

- No space constraints or color figure charges

- Immediate publication on acceptance

- Inclusion in PubMed, CAS, Scopus and Google Scholar

- Research which is freely available for redistribution

Submit your manuscript at www.biomedcentral.com/submit
Biomed Central 